\title{
Manda quem pode: a elite governante da cultura em Portugal (1976-2011)
}

Após o 25 de abril de 1974, o processo de democratização promoveu na sociedade portuguesa um debate em torno de "o que é a cultura?", "o que é que a política pode fazer por ela?" e "quem a governa?", tendo ficado consagradas na Constituição da República Portuguesa as expectativas desse período ${ }^{1}$.

Capítulo III - Direitos e deveres culturais

Artigo 73. - (Educação, cultura e ciência)

1. Todos têm direito à educação e à cultura.

(...)

3. O Estado promove a democratização da cultura, incentivando e assegurando o acesso de todos os cidadãos à fruição e criação cultural, em colaboração com os órgãos de comunicação social, as associações e fundações de defesa do patrimônio cultural, as organizações de moradores e outros agentes culturais.

Constituição da República Portuguesa, 1976

Doutoranda em Ciência Política na Universidade Nova de Lisboa (Lisboa, Portugal) e pesquisadora associada do Observatório Político. E-mail: patriciaoliveira@observatoriopolitico.pt

** Doutorando em Ciência Política na Universidade Nova de Lisboa (Lisboa, Portugal) e pesquisador associado do Observatório Político. E-mail: vargascarlos@live.com.pt

1 Os autores agradecem à Professora Doutora Cristina Montalvão Sarmento, diretora do Observatório Político, o acolhimento humano e científico que tem permitido um sustentado trabalho de investigação. Uma parte significativa do trabalho dos autores é-lhe imensamente devida. Um agradecimento também ao Dr. Pedro Fragoso, membro associado do Observatório Político, pela ajuda atenta e paciente na recolha de informação biográfica. 
Passadas três décadas desde o 25 de Abril de 1974, Portugal enfrenta uma violenta crise econômica e financeira que parece testar os mecanismos do regime democrático, entretanto consolidado. A mudança abrupta de referenciais de democratização cultural e de modernização para um omnipresente referencial de mercado - em que grande parte dos projetos e dos seus valores adjacentes só são válidos em função de uma comprovada sustentabilidade - estabelece o momento de crise, obrigando a repensar na totalidade a intervenção e organização no campo cultural.

Neste contexto, o papel dos partidos políticos revela-se fundamental e naturalmente dependente da sua própria estabilidade e posição face ao modo como deve ser entendida, suportada e governada a cultura.

No presente artigo pretendemos dar enquadramento a esta conjuntura crítica, tendo como ponto de referência a seguinte questão: como se caracteriza a elite governante da cultura em Portugal, desde o I ao XVIII Governos Constitucionais, no período compreendido entre 1976 e 2011?

Entre 1995 e 2011, ocuparam a pasta da cultura 8 ministros e 10 secretários de Estado ${ }^{2}$. Desta constante mudança de atores políticos, resultou uma crescente deriva para o setor - uma incapacidade de trabalhar em rede de forma estável, a impossibilidade real de assumir compromissos consensuais aos partidos do arco do poder e transferíveis de governo para governo.

Pensar a cultura e as políticas públicas culturais é pensar no sistema de valores e crenças imperativos a uma sociedade e na forma como o sistema político reconhece legitimidade aos atos do poder administrativo.

$\mathrm{O}$ estudo das elites governantes da cultura surge-nos no âmago das alterações sociais e políticas que marcaram a segunda metade do século XX que, autores como como Weber (1979), Adorno (2003) e Dèbord (2010) diagnosticaram antecipadamente, fizeram com que as elites intelectuais, gestoras e burocráticas ganhassem proeminência na criação de novas formas de organização social (Bottomore, 1964, p. 63).

No entanto, os contributos de Weber (1979), Adorno (2003) e Dèbord (2010) foram ultrapassados pelo modo com hoje pensamos a nossa relação com a cultura; mais do que a nossa curiosidade sobre o que é, desenvolve-se um interesse manifesto sobre o que podemos fazer com ela (Pratt, 2007), isto

A esse propósito, a 6 de junho de 2001, Augusto M. Seabra escreve no jornal diário Público: “De 2000 para cá tem sido uma correria, nenhuma outra pasta teve sete titulares em 11 anos! Assim, pura e simplesmente, não são possíveis políticas sustentáveis". 
é, quais as suas potencialidades no contexto das democracias contemporâneas (Inglehart, 1990; Norris, 1999).

O crescimento econômico nos países desenvolvidos parece favorecer a afirmação de novos valores e interesses culturais (Inglehart, 1990), nomeadamente, a perceção de que a cultura se tornou um produto comercial (Pratt, 2007; Sarmento, 2009), orientou o debate para a necessidade de regulação das atividades culturais (Dijan, 2005), de forma a contribuírem para uma maior eficácia na prossecução dos objetivos políticos - “o consumo cultural é o novo pote de mel utilizado para atrair as abelhas investidoras" (Pratt, 2007, p. 200). Deste modo, aliaram-se as noções de capital, custo de oportunidade e de mercado à noção de cultura.

A cultura converteu-se numa ferramenta igualmente importante e de caráter progressista para os discursos políticos (Sarmento, 2008; 2009). É consensual que a valorização e investimento nos recursos humanos domésticos constituem uma mais-valia para as famílias, para as comunidades e para os Estados, já que se propagou o lema que "sem cultura não há educação e que sem educação não há cultura”. Ao nível externo, a dimensão discursiva apoiou-se na promoção do multiculturalismo e na necessidade de sustentabilidade como garantia de uma cultura de paz e de boa convivência no sistema internacional.

Não é fácil definir o que é uma elite intelectual, sobretudo, determinar qual a sua influência social (Bottomore, 1964, p. 64). Contudo, podemos considerar que fazem parte da elite intelectual os indivíduos com um nível de escolaridade elevado. Os intelectuais são geralmente um grupo restrito de indivíduos, de classe média, que ocupam lugares no ensino e jornalismo, que contribuem diretamente para a criação e crítica artística e das ideias; são escritores, artistas, cientistas, filósofos, teólogos, e comentadores políticos.

Embora não seja fácil delimitar igualmente o campo das atividades intelectuais, este claramente é composto por indivíduos, cujas preocupações são a cultura e a sociedade. Já Mosca (apud Bottomore, 1964) acreditava que os intelectuais, mais do que qualquer outro grupo de interesse, poderiam facilmente deslindar os objetivos sociais ${ }^{3}$.

" (...) se existe alguma classe social preparada para colocar de parte, ainda que por algum tempo, o interesse privado e que seja capaz de compreender o bem comum com o distanciamento necessário, essa será certamente aquela que, graças à sua exigente formação intelectual, tem aquilo que compõe a nobreza, o carácter, os horizontes amplos e as capacidades amplificadas (...), essa classe, e só essa classe, irá sacrificar de bom grado um bem presente, de forma a evitar um mau futuro" (Mosca apud Bottomore, 1964, p. 66-67). 
Se é verdade que a elite social surge fragmentada, a elite política também não é, por sua vez, mais homogênea. A diversidade assenta nos padrões de recrutamento, coesão e permeabilidade (Bessa, 1993, p. 563) que variam consoante as conjunturas ${ }^{4}$. Fruto do desenvolvimento econômico e social conducentes à especialização, a elite social tem a possibilidade de se tornar elite governante, adaptando-se à estrutura burocrática e legitimando-se nas suas atividades, em setores privilegiados como a cultura, educação e comunicação social.

Atualmente, por força da forte mobilidade social não há uma necessária coincidência nem estabilidade entre as elites políticas, as elites sociais e as elites intelectuais. O que se poderá pretender detetar são as disparidades entre as elites ou as suas tendências (Guedes, 2009). O sociólogo António Barreto (2011), observador atento da situação social em Portugal, afirmou recentemente ao jornal Público: "Há 30 ou 40 anos, um político tinha uma visão global, hoje os ministros só falam da sua pasta, e fazem constantemente o elogio do pragmatismo". Acontece que os políticos, como um espelho, refletem a transformação da sociedade portuguesa: de uma lógica territorial (rural e dispersa, logo horizontal) para uma lógica setorial (urbana e especializada, agora vertical), verificando-se a emergência de uma sociedade contemporânea, de interesses divergentes e em constante competição.

A especialização profissional e o desenraizamento territorial são sintomas evidentes e generalizados de um complexo processo de transformação das sociedades contemporâneas ocidentais, e da portuguesa muito em particular.

Perante severas e rápidas transformações do Estado, com interferências evidentes na vida dos cidadãos, perante crescentes tensões e conflitos latentes é fundamental que um discurso político agregador ocupe o espaço público e cumpra a sua função de tradutor da ação pública governamental mas também de moderador das tensões sociais dos diversos grupos em competição.

A política como profissão, daquele que vive para a política e da política, estabelece, assim, o ofício de gestão interdependente, não só da sua carreira profissional, como também dos recursos de que dispõe. De acordo com o binômio intelectual/profissional - como se caracteriza a elite governante da cultura em Portugal, desde o I ao XVIII Governos Constitucionais, no período compreendido entre 1976 e 2011 ?

${ }^{4}$ Para melhor compreender estas variações, veja-se as diferentes designações que a tutela política da Cultura foi assumindo ao longo dos anos (ver Anexo I e II). 


\section{Elite governante da cultura: perfil de recrutamento em perspetiva comparada}

Os governos influenciam em pouco ou nada a criação de novos sentimentos, a formação de novos resíduos ou a modificação dos que já existem. A arte de governar consiste principalmente em extrair benefícios dos sentimentos existentes no país.

(Pareto, 1975, p. 244)

Para efeitos de análise prosopográfica, consideramos os perfis de seleção ${ }^{5}$ dos Ministros, Secretários e Subsecretários ${ }^{6}$ de Estado da Cultura, em Portugal, desde o I ao VXIII Governos Constitucionais, no período compreendido entre 1976 e $2011^{7}$, tendo ponderado as suas características demográficas (idade e gênero), credenciais acadêmicas, as carreiras profissionais e políticas, bem como as suas eventuais competências no setor da cultura.

\section{Idade}

Tabela 1 - Distribuição etária da elite governante da cultura* (em percentagem**)

\begin{tabular}{|c|c|c|c|c|c|c|c|}
\hline \multirow{2}{*}{ cargo } & \multicolumn{6}{|c|}{ grupos etários } & \multirow{2}{*}{$\begin{array}{l}\text { Idade } \\
\text { média }\end{array}$} \\
\hline & $30-35$ & $36-40$ & $41-50$ & $51-55$ & $56-60$ & $61-65$ & \\
\hline $\begin{array}{l}\text { ministros da Cultura } \\
\qquad(\mathrm{N}=13)\end{array}$ & 0 & 15,4 & 30,8 & 23,1 & 15,4 & 15,4 & 50 \\
\hline $\begin{array}{l}\text { secretários de Estado da } \\
\text { Cultura }(\mathrm{N}=21)\end{array}$ & 19 & 42,9 & 28,6 & 4,8 & 0 & 4,8 & 39 \\
\hline
\end{tabular}

* Idade dos ministros e secretários de Estado da Cultura quando da sua primeira nomeação para o governo (1976-2010).

${ }^{* *}$ A soma das percentagens poderá não totalizar $100 \%$ devido aos arredondamentos.

$\mathrm{N}=$ número de casos conhecidos.

A informação biográfica recolhida para elaboração dos perfis sociais, profissionais e políticos foi obtida a partir de fontes governamentais acessíveis on-line (portal do Governo de Portugal, do antigo Ministério da Cultura, da Presidência do Conselho de Ministros, da Assembleia da República, do Ministério da Educação e do Instituto Camões, Ministério dos Negócios Estrangeiros) e pelos documentos gentilmente disponibilizados pela Secretaria-Geral do ex-Ministério da Cultura - Direção de Serviços de Relações Públicas, Documentação e Arquivo, bem como através da realização de entrevistas informais a alguns dos membros da elite governante da cultura, em Portugal.

6 Para efeitos de análise estatística doravante os Subsecretários de Estado da Cultura estão sempre incluídos na categoria de Secretários de Estado da Cultura.

Para o período referido, veja-se o Anexo I e Anexo II. 
No que concerne às características demográficas, o indicador idade permite-nos salientar alguns aspetos comparativos relevantes. Analisando a distribuição etária dos Ministros e Secretários de Estado da Cultura, no momento da sua primeira nomeação para o Governo, podemos verificar que há um predomínio do segmento de indivíduos de "meia-idade" (41-50 anos), embora a média de idades seja mais elevada no cargo de Ministro da Cultura (50 anos) do que no cargo de Secretário de Estado da Cultura (39 anos).

Importa ainda referir que nos restantes grupos etários, o cargo de Secretário de Estado da Cultura é aquele que apresenta maior percentagem de indivíduos de classe jovem (42,9\%), concentrando mais de metade dos indivíduos com idade inferior a 40 anos, por ocasião da sua estreia no elenco governativo.

\section{Origens geográficas de nascimento}

Tabela 2 - Origem geográfica de nascimento da elite governante da cultura* (em percentagem**)

\begin{tabular}{c|c|c|c|c|c}
\hline \multirow{2}{*}{ cargo } & \multicolumn{5}{|c}{ origem geográfica } \\
\cline { 2 - 6 } & lisboa $^{\text {a) }}$ & porto $^{\text {b) }}$ & resto do país & ex-colônias & estrangeiro \\
\hline ministros da Cultura (N=13) & 41,2 & 11,8 & 17,6 & 11,8 & 0 \\
\hline secretários de Estado da Cultura (N=20) & 70 & 0 & 20 & 0 & 10 \\
\hline
\end{tabular}

*Origem geográfica de nascimento dos ministros e secretários de Estado da Cultura quando da sua primeira nomeação para o governo (1976-2010).

${ }^{* *}$ A soma das percentagens pode não totalizar $100 \%$ devido aos arredondamentos.

$\mathrm{N}=$ número de casos conhecidos.

a) Área metropolitana de Lisboa.

b) Área metropolitana do Porto.

A literatura disponível sobre elites e recrutamento ministerial, no caso português (Almeida, Pinto e Bermeo, 2006, p. 35; Almeida e Pinto, 2009), evidencia que as diferenças e assimetrias territoriais - urbanas e rurais - são indicadores mais apropriados do que as identidades regionais, no caso dos demais países da Europa do Sul (Almeida, Pinto e Bermeo, 2006). Deste modo, verificamos que a percentagem de Ministros da Cultura $(41,2 \%)$ e de Secretários de Estado da Cultura (70\%), cuja origem geográfica de nascimento em Lisboa, é claramente superior face à percentagem de indivíduos oriundos do Porto $(11,8 \%)$ ou das restantes zonas do país. Note-se, para 
além disso, que é maior a proeminência de indivíduos oriundos de Lisboa naqueles que exercem o cargo de Secretário de Estado da Cultura.

A determinação da origem geográfica de nascimento no recrutamento ministerial para os governos constitucionais pós 25 de Abril constitui uma marca distintiva da experiência histórica, política e cultural do Portugal contemporâneo. É no contexto da III vaga de democratização (Huntington, 1999), e com o processo de descolonização, que registamos de forma relevante a percentagem de $11,8 \%$ de indivíduos, cuja origem geográfica de nascimento são as ex-colônias portuguesas, ainda que esta percentagem seja reduzida face ao total de casos considerados.

Fazemos referência igualmente, aos locais de nascimento no estrangeiro, sendo a percentagem de 10\% para o cargo de Secretário de Estado da Cultura.

Tendo por referência os estudos empíricos anteriormente realizados sobre o recrutamento ministerial (Almeida, Pinto e Bermeo, 2006; Almeida e Pinto, 2009; Magone, 2003; Guedes, 2009), também a origem geográfica, especificamente para o setor da governação da cultura, não exclui ou diminui a elevada representação de Lisboa (seguida da cidade do Porto), bem como realça a predomínio das grandes cidades como "viveiros do recrutamento ministerial".

Por conseguinte, os dados recolhidos no âmbito deste setor da governação confirmam a tendência macrocéfala da organização territorial portuguesa em áreas metropolitanas e a centralização do recrutamento da elite às áreas metropolitanas de Lisboa e Porto.

\section{Credenciais acadêmicas}

Tabela 3 - Formação acadêmica da elite governantes da cultura* (em percentagem**)

\begin{tabular}{c|c|c|c}
\hline \multirow{2}{*}{ cargo } & \multicolumn{3}{|c}{ grau universitário } \\
\cline { 2 - 4 } & ensino secundário & licenciatura & doutoramento \\
\hline ministros da Cultura (N=13) & 7,7 & 38,5 & 53,8 \\
\hline secretários de Estado da Cultura (N=22) & 0 & 68,2 & 31,8 \\
\hline
\end{tabular}

*Fomação acadêmica dos ministros e secretários de Estado da Cultura quando da sua primeira nomeação para o governo (1976-2010).

${ }^{* *}$ A soma das percentagens pode não totalizar $100 \%$ devido aos arredondamentos.

$\mathrm{N}=$ número de casos conhecidos. 
A distribuição por graus de ensino ${ }^{8}$ dos Ministros e Secretários de Estado da Cultura, constitui um dos indicadores relevantes sobre a formação e qualificação desta elite. No que diz respeito às suas credenciais acadêmicas, os resultados obtidos seguem historicamente as tendências registadas na literatura analisada sobre recrutamento ministerial em anteriores regimes políticos (Almeida, Pinto e Bermo, 2006, p. 37-38; Guedes, 2009).

No caso contemporâneo português, verificamos que a esmagadora maioria dos Ministros e Secretários de Estado da Cultura possuem estudos ao nível superior ${ }^{9}$. Os resultados obtidos através da agregação e comparação de $\operatorname{casos}^{10}$ são expressivos da configuração de uma elite governante da cultura possuidora de um diploma universitário (Guedes, 2009, p. 269) e, por conseguinte, altamente qualificada ${ }^{11}$.

Através da análise dos dados disponíveis sobre a formação acadêmica desta elite, podemos destacar os seguintes aspetos: para além de todos os indivíduos possuírem um nível de escolaridade superior, verificamos igualmente, uma percentagem expressiva de indivíduos que possuem formação superior ao nível de licenciatura e de doutoramento, quando da sua estreia no Governo. No caso dos Ministros da Cultura a aquisição do diploma de licenciatura $(38,5 \%)$ é menos relevante do que a percentagem de indivíduos doutorados $(53,8 \%)$ - os resultados apontam, por isso, para a polarização da formação acadêmica entre Ministros da Cultura licenciados e doutorados.

Quanto ao cargo de Secretário de Estado da Cultura, observamos uma preponderância significativa para a atribuição do cargo àqueles que possuem estudos superiores, ao nível da licenciatura (68,2\%); apuramos, ainda, que 31,8\% dos Secretários de Estado da Cultura possuem estudos no nível de doutoramento.

O O grau de pós-graduação não foi contabilizado.

- Salvo exceção de um único caso, devidamente assinalado.

10 Guedes (2009, p. 269) salienta o seguinte, no caso dos padrões de carreira dos primeiros-ministros europeus: "a existência de uma formação acadêmica superior é uma marca distintiva de quase todos os líderes de governo, atingindo os 92\%. Portugal, a Espanha e a Grécia destacam-se de novo por uma maior predominância da educação universitária: todos os primeiros-ministros são licenciados".

1 Pese embora os indivíduos que tenham completado os estudos pós-graduados não tenham sido contabilizados, uma vez que têm fraca expressão no universo considerado, não poderemos deixar de fazer referência à aquisição de competências técnicas e à aposta na formação técnica nos níveis de pós-graduação. 
Uma vez comentados os graus de formação acadêmica da elite governante da cultura importa maximizar a variância dos dados, cruzando-os com as respetivas áreas de formação acadêmica.

Tabela 4 - Áreas de formação acadêmica da elite governante da cultura* (em percentagem ${ }^{* *}$ )

\begin{tabular}{c|c|c}
\hline \multirow{2}{*}{ área de formação } & \multicolumn{2}{|c}{ cargo } \\
\cline { 2 - 3 } & $\begin{array}{c}\text { ministros da } \\
\text { Cultura (N=13) }\end{array}$ & $\begin{array}{c}\text { secretários de Estado } \\
\text { da Cultura (N=20) }\end{array}$ \\
\hline ciências musicais & 7,7 & 10 \\
\hline ciência política & 7,7 & 15 \\
\hline direito & 23,1 & 25 \\
\hline economia & 7,7 & 10 \\
\hline humanidades & 38,5 & 40 \\
\hline
\end{tabular}

*Área de formação dos ministros e secretários de Estado da Cultura quando da sua primeira nomeação para o governo (1976-2010).

${ }^{* *}$ A soma das percentagens pode não totalizar $100 \%$ devido aos arredondamentos.

$\mathrm{N}=$ número de casos conhecidos.

No que concerne às áreas de formação acadêmica dos Ministros e Secretários de Estado da Cultura, a licenciatura em Direito mantém-se como requisito fundamental para aceder aos lugares de poder na arena política em geral, e na cultura em particular. Entre aqueles que ocupam o cargo de Ministro da Cultura neste setor particular da governação, 23,1\% possuem formação em Direito; menor é a percentagem de Secretários de Estado da Cultura com formação naquela área, muito embora atinjam mais de um terço em relação ao total de indivíduos com o mesmo cargo.

Do mesmo modo, o tratamento do conjunto da informação biográfica disponível permite-nos confirmar a inferência dos autores Almeida e Pinto (2009, p. 151) para o caso dos Ministros portugueses: a presença de Ministros da Cultura e de Secretários de Estado da Cultura com formação jurídica tende a ser maior nos partidos de direita.

No entanto, regista-se um aumento da formação nas áreas da Economia e da Ciência Política, cujo objetivo poderá traduzir-se na crescente necessidade em corresponder a um conjunto de desafios e potencialidades 
atuais no setor da cultura, entre os quais se destacam: a necessidade crescente de, a par da redação jurídica dos concursos, racionalizar os recursos econômicos e a atribuição dos subsídios à criação artística; o interesse renovado pelas indústrias culturais e criativas como fator impulsionador e gerador de riqueza econômica (Pratt, 2007); o acesso à cultura como indicador relevante sobre padrões de desenvolvimento social, condições de bem-estar e de cidadania (Inglehart, 1990); a vertente de internacionalização da cultura e valorização do patrimônio, nas áreas do turismo e da política externa.

Para além disso, não podemos deixar de referir que, devido às atribuições e características específicas deste setor da governação, encontramos perfis de recrutamento com formação pontualmente diversificada em outras áreas tipicamente associadas às elites intelectuais (Bottomore, 1964, p. 64) - História, Filologia Clássica, Filosofia, Literatura, Ciências Musicais.

Contrariamente à ideia de que as qualificações acadêmicas atuam como mecanismos de restrição no campo do recrutamento político (cf. Almeida, Pinto e Bermo, 2006, p. 37), se considerarmos a evolução das competências do próprio órgão, bem como as suas diversas designações ${ }^{12}$, a qualificação acadêmica ou o grau de escolaridade constituem fatores importantes de distinção social, de valorização do perfil e de reconhecimento entre os seus pares daqueles que são chamados a assumir a pasta dos assuntos culturais.

Nesse sentido, ainda, uma análise estrutural e individual poderá trazer benefícios na compreensão sistêmica, mas matizada, dos padrões de recrutamento ministerial (Cotta, 2008, p. 118) - este artigo incide nessa vertente de investigação, ao concentrar-se no perfil individual e biográfico dos indivíduos, extraindo e valorizando as suas responsabilidades governativas, num setor específico e particular como é a cultura.

Uma leitura paralela dos graus de formação acadêmica e das áreas de formação permite-nos diagnosticar que um perfil qualificado e especializado tem mais hipóteses de granjear sucesso na prossecução das responsabilidades que lhes estão adstritas.

12 Veja-se o Anexo I (Ministros da Cultura ou Ministros com a tutela política do setor) e Anexo Il (Secretários e Subsecretários de Estado da Cultura). 
Tabela 5 - Local de formação acadêmica da elite governante da cultura* (em percentagem*)

\begin{tabular}{c|c|c|c|c}
\hline \multirow{2}{*}{ cargo } & \multicolumn{4}{|c}{ local de formação acadêmica } \\
\cline { 2 - 5 } & lisboa & coimbra & porto & estrangeiro \\
\hline ministros da Cultura (N=13) & 69,2 & 7,7 & 7,7 & 15,4 \\
\hline secretários de Estado da Cultura (N=19) & 57,9 & 10,5 & 0 & 31,6 \\
\hline
\end{tabular}

* Local de formação dos ministros e secretários de Estado da Cultura quando da sua primeira nomeação para 0 governo (1976-2010).

**A soma das percentagens pode não totalizar $100 \%$ devido aos arredondamentos.

$\mathrm{N}=$ número de casos conhecidos.

No que concerne aos locais de formação acadêmica reencontramos o mesmo padrão de macrocefalia urbana, anteriormente explicado no indicador origens geográficas. No entanto, importa explicitar algumas diferenças e diagnósticos que decorrem dos dados reunidos nesta seção - credenciais acadêmicas.

As transformações do Portugal democrático e o alargamento do ensino universitário por todo o território nacional não nos permitem concluir que o recrutamento se faz de forma dispersa e equilibrada. Podemos afirmar, no entanto, que a macrocefalia da cidade de Coimbra, com a sua antiga Universidade, foi substituída pela macrocefalia de Lisboa.

Analisando os perfis dos Ministros e Secretários de Estado da Cultura verificamos que, dada a formação predominante na área do Direito, a fonte de recrutamento institucional privilegiada passou a ser a Faculdade de Direito de Lisboa (FDL).

Nas restantes áreas de formação em Humanidades - que incluem formação em Literatura, Filologia, Filosofia, História - a Faculdade de Letras de Lisboa, surge novamente como local de formação preferencial, seguida pelo Instituto Superior de Ciências do Trabalho e da Empresa (ISCTE) nas áreas de formação em Sociologia e Economia.

Quanto às áreas de formação em Ciência Política, o ensino privado português surge no ranking através da Universidade Católica Portuguesa Lisboa (UCP).

Se aplicarmos a expressão de "cosmopolitismo intelectual", este tem maior evidência na percentagem de licenciados e doutorados por universidades estrangeiras - 15,4\% no caso dos Ministros da Cultura, e 31,6\% no caso dos Secretários de Estado. A análise da literatura (Almeida, Pinto e Bermeo, 2006, 
p. 40) permite-nos confirmar que a formação em universidades estrangeiras tem sido uma fonte de recrutamento ministerial relevante com a entrada do I Governo Constitucional, em 1976.

Tal como explanado na literatura e corroborado na análise biográfica da elite governante da cultura, nos Governos Constitucionais, a partir de 1976, regista-se uma preferência por aqueles que estudaram no Reino Unido, licenciando-se em áreas específicas como a História, as Ciências Musicais, a Física e a Economia.

Tal como temos demonstrado a formação acadêmica superior é um requisito essencial para a formação de uma elite potencialmente intelectual e, portanto, mais habilitada na administração dos assuntos culturais, o que pode ser explicado, em seguida, pela importância dos professores universitários nos padrões de recrutamento profissional.

\section{Padrões de carreira profissional}

Tabela 6 - Padrões de carreira da elite governante da cultura* (em percentagem ${ }^{* *}$ )

\begin{tabular}{c|c|c}
\hline \multirow{2}{*}{ categorias profissionais } & \multicolumn{2}{|c}{ cargo } \\
\cline { 2 - 3 } & $\begin{array}{c}\text { ministros da } \\
\text { Cultura (N=13) }\end{array}$ & $\begin{array}{c}\text { secretários de Estado } \\
\text { da Cultura (N=22) }\end{array}$ \\
\hline professor universitário / Pesquisador & 38,5 & 36,4 \\
\hline dirigente da Administração Pública & 7,7 & 27,3 \\
\hline funcionário público & 7,7 & 9,1 \\
\hline Político profissional & 15,4 & 18,2 \\
\hline advogado / jurista & 15,4 & 9,1 \\
\hline gestor cultural & 15,4 & 0 \\
\hline
\end{tabular}

* Categorias profissionais dos ministros e secretários de Estado da Cultura quando da sua primeira nomeação para 0 governo (1976-2010).

${ }^{* *}$ A soma das percentagens pode não totalizar $100 \%$ devido aos arredondamentos.

$\mathrm{N}=$ número de casos conhecidos.

Através dos dados constantes da Tabela 6, constatamos que o recrutamento para o cargo de Ministro da Cultura é feito preferencialmente na categoria de professor universitário / pesquisador (38,5\%). Os políticos profissionais apenas contribuem com $23 \%$ para o mesmo cargo.

Já no que respeita ao cargo de Secretário de Estado, 36,4\% dos recrutados são oriundos da categoria de professor universitário/ pesquisador, a que se 
juntam 27,3\% de recrutados entre dirigentes da administração pública ou funcionários públicos (técnicos superiores). Na verdade, estes dois grupos são oriundos do universo da administração pública, pelo que correspondem a um conjunto hegemônico de 72,8\%. Para o cargo de Secretário de Estado, apenas $18,2 \%$ dos recrutados são oriundos da categoria político profissional.

Segundo os padrões de recrutamento profissional, a preponderância da categoria profissional professor universitário/pesquisador está também correlacionada com o crescente protagonismo dos independentes ou tecnocratas no executivo (Almeida e Pinto, 2009, p. 151).

Para além disso, no que diz respeito aos padrões de carreira profissional dos Ministros e Secretários de Estado da Cultura podemos observar que o elenco de profissões não é muito diversificado, havendo uma concentração expressiva, tal como já se referiu, na categoria de professor universitário, seguida da categoria de político profissional. Importa mencionar que os professores de Direito foram perdendo preponderância face às outras áreas de formação já mencionadas (Almeida, Pinto e Bermeo, 2006).

A partir destes dados atestamos uma correlação positiva entre a literatura disponível sobre a formação das elites intelectuais (Bottomore, 1964; Bessa, 1993, p. 604) e os padrões de recrutamento nos estudos empíricos realizados (Almeida, Pinto e Bermeo, 2006; Almeida e Pinto, 2009).

A produção teórica e empírica tem demonstrando que a transição para a democracia reforçou os padrões de recrutamento entre os indivíduos de classe média-alta, com níveis de escolaridade superior e "independentes" dos circuitos partidários - Magone (2003, p. 329) apelida esta classe política de "academocracy", um neologismo virtuoso para explicar a presença e importância da elite de acadêmicos nas diversas pastas ministeriais e no processo de consolidação democrática.

Se é certo que nem todos os professores universitários são provenientes dos escalões de topo da hierarquia universitária, não podemos ignorar que existem algumas exceções importantes - como no caso do primeiro Secretário de Estado da Cultura do XVII Governo Constitucional (2005-2009) a quem, à data da sua nomeação, eram atribuídas funções de vice-reitor; ou no caso dos indivíduos, que com experiência na área da investigação científica, se graduaram em universidades estrangeiras de prestígio internacional.

Quanto à experiência política, uma análise mais alargada das respetivas biografias faculta-nos uma maior abrangência e detalhe quanto ao percurso 
e experiências profissionais dos indivíduos que compõem a elite governante da cultura. Por conseguinte, registamos a valorização dos trabalhos de assessoria desenvolvidos no âmbito do Ministério dos Negócios Estrangeiros. Já a experiência parlamentar (Almeida, Pinto e Bermeo, 2006, p. 52) é mais importante no recrutamento dos Secretários de Estado da Cultura, do que no recrutamento de Ministros da Cultura.

Conforme a literatura indica (Magone, 2003, p. 329), a Assembleia da República é considerada a arena privilegiada de formação dos políticos profissionais, podendo proporcionar a ascensão a cargos de presidência de comissões parlamentares ou a membros do governo. No caso dos Ministros da Cultura, a experiência noutros ministérios é valorizada, sendo mais sensíveis a mudanças de pastas, quando das remodelações dentro do governo ${ }^{13}$.

Tal como evidencia Garcês (2009, p. 264), a elite política constitui uma espécie de "bolsa de políticos que se vão revezando entre si no exercício do poder, independentemente de títulos, qualificações, cargos e funções”. Contudo, o exercício do cargo ministerial não exige a eleição prévia para o Parlamento, pelo que, como já registámos, o recrutamento entre professores universitários independentes é manifesto, assim como a autonomia do Primeiro-Ministro indigitado na escolha dos seus ministros (Almeida e Pinto, 2009).

Nas restantes categorias profissionais, pelo que a análise dos perfis biográficos nos permitiu comprovar, todas elas se desenvolveram em parceria com o Estado. Por um lado, aqueles que alçaram o lugar de Secretários de Estado da Cultura provieram, uma parte, do contingente de funcionários públicos superiores com funções de assessoria em gabinetes ministeriais. Por outro lado, não foi surpreendente verificar que aqueles que exerciam funções como advogados ou juristas $(15,4 \%)$ se especializaram no aconselhamento jurídico e de auditoria nos setores da cultura e negócios estrangeiros dos respetivos Ministérios, assumindo posteriormente, o cargo de Secretários de Estado - pelo que se pôde verificar, nos últimos anos, a passagem de pastas entre estes dois setores.

No cômputo geral, podemos observar que, para se atingir a posição de Ministro da Cultura ou de Secretário de Estado da Cultura, possuir expe-

\footnotetext{
${ }^{3}$ No âmbito do Ministério da Cultura verificamos apenas duas mudanças de pasta - a primeira, no XIV Governo Constitucional (1999-2002) e a segunda, no VXII Governo Constitucional (2005-2009). No âmbito da Secretaria de Estado da Cultura verificamos remodelações no XII Governo Constitucional (1991-1995) liderado por Cavaco Silva, no I e ll governos de António Guterres (1995-1999; 1999-2002), no XVI Governo Constitucional (2004-2005) liderado por Santana Lopes (antigo Secretário de Estado da Cultura) e no VXII (2005-2009) Governo Constitucional liderado pelo anterior Primeiro-Ministro, José Sócrates.
} 
riência política é menos relevante do que possuir experiência na área da docência e da investigação. Este nosso argumento pode ser maximizado aferindo que os cargos de Ministro da Cultura e de Secretário de Estado da Cultura não são cargos ambicionados por políticos profissionais e, por essa razão também, estas pastam possuem um pendor menos politizável.

Paralelamente, se nos permitirmos a uma leitura mais livre das biografias ${ }^{14}$ da elite governante da cultura verificamos que uma parte considerável dos indivíduos se dedica a atividades ligadas à produção literária e ensaística, à interpretação musical e dramatúrgica.

É neste encalço entre cultura, política e elites no geral, que consideramos relevante mencionar a existência de uma discussão pública, que se faz nas margens da política institucional, mas que tem vindo progressivamente a modelar e a estreitar essas mesmas margens de influência no sistema da cultura e na administração da pasta.

A discussão pública acerca das práticas culturais e sobre o domínio formal do Estado sobre o setor tem sido, ela própria, dominada por uma elite que discute os fenômenos como possibilidade de mobilidade social e, ao mesmo tempo, como meio para a convocação de um ideário que oscila entre o apelo a utopias redentoras ou a pragmatismos conservadores. Esta discussão ocorre essencialmente na imprensa escrita e vai dando conta das tensões resultantes dessa desagregação social que afeta a sociedade portuguesa.

A discussão oscila regularmente entre a defesa de políticas carismáticas de direita e os valores da democratização cultural típicos da esquerda. A direita refugia-se na defesa intransigente do patrimônio como valor único de salvaguarda da identidade nacional, a par de uma confiança desmesurada nas capacidades do mercado no que diz respeito à criação contemporânea enquanto a esquerda promove a defesa da democratização cultural através do apoio à criação contemporânea e do alargamento dos públicos.

Este debate público na imprensa tem deixado transparecer igualmente, a luta de interesses mais corporativos e menos ideológicos em que os públicos são entidades cada vez mais distantes, consumidos que estão os atores políticos na eterna discussão da natureza do setor, da sua efetiva existência, da sua necessidade, do seu valor cultural e econômico, da sua sustentabilidade.

\footnotetext{
${ }^{14} \mathrm{Na}$ tentativa de examinar com maior detalhe as relações entre cultura e política, numa análise mais detalhada, é inevitável salientar a presença de dois Ministros e de um Secretário de Estado da Cultura, enquanto quadros superiores de uma importante fundação cultural portuguesa.
} 
É nesse contexto que fazemos referência aos textos de Augusto M. Seabra (2011a; 2011b), Vasco Pulido Valente ou Pacheco Pereira, publicados na imprensa de referência portuguesa.

\section{Padrões de carreira política}

Tabela 7- Experiência em partidos políticos da elite governante da cultura* (em percentagem ${ }^{* *}$ )

\begin{tabular}{c|c|c|c}
\hline & & $\begin{array}{c}\text { ministros da } \\
\text { Cultura (N=13) }\end{array}$ & $\begin{array}{c}\text { secretários de Estado } \\
\text { da Cultura (N=22) }\end{array}$ \\
\hline \multirow{4}{*}{$\begin{array}{c}\text { Participação em } \\
\text { partidos políticos }\end{array}$} & Filiação & 53,8 & 54,5 \\
\cline { 2 - 4 } & PS & $\begin{array}{c}\text { ministros da } \\
\text { Cultura (N=7) }\end{array}$ & $\begin{array}{c}\text { secretários de Estado } \\
\text { da Cultura (N=12) }\end{array}$ \\
\cline { 2 - 4 } & PSD & 57,1 & 25 \\
\cline { 2 - 4 } & CDS & 28,6 & 58,3 \\
\cline { 2 - 4 } & líderes partidários & 14,3 & 16,7 \\
\hline
\end{tabular}

*Participação em partidos políticos dos ministros e secretários de Estado da Cultura quando da sua primeira nomeação para o governo (1976-2010).

${ }^{* *}$ A soma das percentagens pode não totalizar $100 \%$ devido aos arredondamentos.

$\mathrm{N}=$ número de casos conhecidos.

PS (Partido Socialista)

PSD (Partido Social Democrata)

CDS (Centro Democrático e Social)

Tal como referimos na secção anterior, a experiência política é relevante para se alcançar um lugar no elenco governativo, embora este mesmo critério não seja decisivo no cargo de Ministro e Secretário de Estado da Cultura. Assim, 53,8\% dos Ministros da Cultura escolhidos para o cargo tinham filiações políticas, sendo a percentagem de $54,5 \%$ para os Secretários de Estado da Cultura. No entanto, verificamos que a elite governante da cultura não possui uma participação ativa relevante nas atividades partidárias, nem tão pouco alguma vez assumiu a lideranças em partidos políticos ${ }^{15}$.

\footnotetext{
15 A percentagem de filiações partidárias pode suscitar equívocos. No entanto, a leitura deste indicador poderá ser influenciado pelo fato de o Ministério da Cultura nos respetivos I, II, IV, VI, XI e XII Governos Constitucionais ter sido tutelado pelo órgão da Presidência do Conselho de Ministros, estando estas funções adstritas ao cargo de Primeiro-Ministro, coincidindo com o líder do partido eleito para formar governo.
} 
Por um lado, os dados registados permitem confirmar o modelo de independentes (Almeida e Pinto, 2009) ligados ao exercício da governação ministerial da cultura. Por outro lado, importa fazer uma alusão histórica ao período de consolidação democrática, no qual os governos de iniciativa presidencial propiciaram a participação de personalidades relativamente independentes da arena política, mas não totalmente fora dos próprios partidos políticos (Almeida, Pinto e Bermeo, 2006, p. 53).

Tal como evidencia Magone (2003, p. 328), o recrutamento da elite governante tem sido monopolizado pelos partidos políticos, mesmo no caso dos independentes, uma vez assumidas as pastas ministeriais, estes são aliciados a filiarem-se nos partidos políticos que os colocaram no poder.

A variação na percentagem de filiações partidárias no cargo de Ministro da Cultura pode ser explicada à luz das remodelações na titularidade das pastas e aos governos de coligação que se estabeleceram em algumas legislaturas. Por seu turno, o número constante de Secretários de Estado com filiações partidárias (54,5\%) vem reforçar a necessidade de coadjuvação técnica nas atividades ministeriais da cultura, mas também reforçar a imagem de competência técnica geral dos governos (Bessa, 1993, p. 296), de forma a combater a frágil integração dos partidos na sociedade civil.

É de reforçar, ainda, a preponderância de Ministros e Secretários de Estado da Cultura com filiação nos dois maiores partidos (PS e PSD), frequentemente designados por "partidos do arco governativo" ou "bloco central".

\section{Gênero}

Tabela 8 - Composição por gênero da elite governante da cultura* (em percentagem)

\begin{tabular}{c|c|c}
\hline cargo & masculino & feminino \\
\hline ministros da Cultura $(\mathrm{N}=\mathbf{1 3})$ & 76,9 & 23,1 \\
\hline secretários de Estado da Cultura $(\mathrm{N}=\mathbf{2 2})$ & 72,7 & 27,3 \\
\hline
\end{tabular}

*Participação em partidos políticos dos Ministros e Secretários de Estado da Cultura quando da sua primeira nomeação para 0 Governo (1976-2010).

Uma das conquistas do Portugal Democrático foi, sem dúvida, a entrada da mulher na vida política ativa. No entanto, sem enveredarmos pelo debate acerca da cultura de paridade e da discriminação positiva, é manifesto o desequilíbrio entre o número de homens e mulheres (Guedes, 2009, p. 
267) no elenco governativo da cultura, principalmente ao nível do cargo de Ministro da Cultura ${ }^{16}$.

De um modo geral, podemos constatar que os cargos são ocupados maioritariamente por homens. No período em análise, a percentagem é sensivelmente mais expressiva para o cargo de Ministro (76,9\%), sendo de 72,7\% para o cargo de Secretário de Estado.

Contudo, se a análise for feita apenas no período compreendido entre 1976 e 2002, verifica-se que o cargo de Ministro da Cultura é ocupado a $100 \%$ por homens, mantendo o cargo de Secretário de Estado da Cultura uma distribuição próxima da do período na sua totalidade $(72,2 \%$ contra $27,7 \%)$. Os dados disponíveis confirmam que, a partir dos anos 90, há uma subida significativa do número de mulheres Secretárias de Estado da Cultura.

De fato, o cargo de Ministro da Cultura só será ocupado por uma mulher, pela primeira vez, no XVI Governo Constitucional (2004-2005), enquanto o cargo de Secretário de Estado foi ocupado por uma mulher, pela primeira vez, logo no III Governo Constitucional (1978). Considerando a cronologia, podemos aferir que a Secretaria de Estado da Cultura foi pioneira ao incluir mulheres nas funções administrativas, verificando-se o mesmo durante o X e XI Governos Constitucionais, no período entre 1985-1987 e 1987-1991, respetivamente.

Por fim, detetamos não haver diferença relevante nos partidos de esquerda e de direita (Almeida e Pinto, 2006, p. 46) na distribuição de pastas por gênero.

\section{Considerações finais}

Da análise do perfil e recrutamento da elite governante da cultura, isto é, do conjunto dos Ministros e Secretários de Estado da Cultura, podemos concluir que esta é uma elite com características e funções específicas, que tendem a articular os padrões de recrutamento político com os requisitos da atividade cultural.

A presente análise prosopográfica não levou em consideração o destino das elites governantes da cultura no pós-exercício do cargo. Uma análise

\footnotetext{
${ }^{16}$ Outros estudos (Almeida, Pinto e Bermeo, 2006; Almeida e Pinto, 2009; Guedes, 2009) evidenciam igualmente a fraca representação feminina na política, quer na escala de análise nacional, quer por efeitos comparativos à escala europeia.
} 
atenta desses percursos poderá permitir leituras de evolução da carreira profissional, e em particular da carreira política, sendo que alguns casos são já muito evidentes.

Assim, este artigo considera exclusivamente o universo de Ministros, Secretários e Subsecretários de Estado da Cultura, tendo-se decidido, desde início, não analisar o universo dos respetivos chefes de gabinete e respetivos assessores e adjuntos. Pese embora não possamos deixar de salientar a crescente importância destes "grupos invisíveis", cuja importância não é despicienda nos mecanismos de decisão política dos gabinetes governamentais, em Portugal. Fica ainda por estudar um conjunto determinante das elites governantes da cultura: trata-se do universo constituído por diretores-gerais, presidentes de conselho de administração de empresas públicas e ainda presidentes de conselho de administração de fundações.

Da presente análise, conclui-se que esta é uma tutela assumida por indivíduos de "meia-idade" quer ao nível dos Ministros quer ao nível dos seus Secretários de Estado. É igualmente indiscutível a formação acadêmica de nível superior, corroborando os requisitos para que esta se forme enquanto elite intelectual. Para além disso, verifica-se o aparecimento de formação acadêmica e carreira profissional nas áreas de gestão e economia, suprindo as necessidades e correspondendo aos desafios atuais da economia cultural. Podemos ainda considerar, que existe uma elite cada vez mais profissional na administração dos assuntos culturais, dado que a experiência em aconselhamento jurídico na área é também bastante valorizada.

Se nos primeiros Governos Constitucionais constatamos uma tendência de compromisso entre elite, ideologia e movimentos sociais, atualmente a elite ministerial da cultura é menos politizada, isto é, as suas atividades seguem o padrão de tecnocracia das burocracias contemporâneas, fruto também da fraca ancoragem dos partidos políticos na sociedade civil portuguesa e neste setor em particular. Também por isso, a ação política faz uma leitura morfológica das situações e atua de forma setorial, circunscrita, sem visão de conjunto, logo sem capacidade agregadora. Por outro lado, a ausência ou escassez de discurso político, a par da presença constante de uma linguagem técnica complexa, acentuam a distância social e impedem o reconhecimento público da ação do Estado ou, dito de outra forma, do Estado em ação. 


\section{Anexo I}

Quadro 1 - Ministros da Cultura ou Ministros com a tutela política do setor (1976-2011)*

\begin{tabular}{|c|c|c|c|}
\hline Governo Constitucional & Titular & Órgão & Cargo \\
\hline $\begin{array}{c}\text { I Governo Constitucional } \\
(1976-78)\end{array}$ & $\begin{array}{c}\text { Joaquim Jorge } \\
\text { de Pinho Campinos }\end{array}$ & --- & Ministro sem pasta \\
\hline $\begin{array}{c}\text { II Governo Constitucional } \\
\text { (1978) }\end{array}$ & $\begin{array}{l}\text { Mário Augusto } \\
\text { Sottomayor Leal Cardia }\end{array}$ & $\begin{array}{l}\text { Ministério da Educação } \\
\text { e Cultura }\end{array}$ & $\begin{array}{c}\text { Ministro da Educação } \\
\text { e Cultura }\end{array}$ \\
\hline $\begin{array}{l}\text { III Governo Constitucional } \\
\text { (1978) }\end{array}$ & $\begin{array}{l}\text { Carlos Alberto } \\
\text { Lloyd Braga }\end{array}$ & $\begin{array}{l}\text { Ministério da Educação } \\
\text { e Cultura }\end{array}$ & $\begin{array}{c}\text { Ministro da Educação } \\
\text { e Cultura }\end{array}$ \\
\hline $\begin{array}{c}\text { IV Governo Constitucional } \\
(1978-1979)\end{array}$ & $\begin{array}{c}\text { Álvaro Pereira da Silva } \\
\text { Leal Monjardino }\end{array}$ & $\begin{array}{c}\text { Presidência do Conselho } \\
\text { de Ministros }\end{array}$ & $\begin{array}{l}\text { Ministro-adjunto do } \\
\text { Primeiro-Ministro }\end{array}$ \\
\hline $\begin{array}{l}\text { V Governo Constitucional } \\
\qquad(1979-1980)\end{array}$ & $\begin{array}{l}\text { Adérito de Oliveira } \\
\text { Sedas Nunes }\end{array}$ & $\begin{array}{c}\text { Ministério da Coordenação } \\
\text { Cultural, Cultura } \\
\text { e da Ciência }\end{array}$ & $\begin{array}{c}\text { Ministro da } \\
\text { Coordenação Cultural, } \\
\text { Cultura e da Ciência }\end{array}$ \\
\hline $\begin{array}{l}\text { VI Governo Constitucional } \\
(1980-1981)\end{array}$ & Francisco Sá Carneiro & $\begin{array}{c}\text { Presidência do Conselho } \\
\text { de Ministros }\end{array}$ & Primeiro-Ministro \\
\hline $\begin{array}{l}\text { VII Governo Constitucional } \\
\text { (1981) }\end{array}$ & Francisco Pinto Balsemão & $\begin{array}{c}\text { Presidência do Conselho } \\
\text { de Ministros }\end{array}$ & Primeiro-Ministro \\
\hline $\begin{array}{l}\text { VIII Governo Constitucional } \\
\text { (1981-1983) }\end{array}$ & $\begin{array}{l}\text { Francisco António } \\
\text { Lucas Pires }\end{array}$ & $\begin{array}{c}\text { Ministério da Cultura e Coorde- } \\
\text { nação Científica }\end{array}$ & $\begin{array}{l}\text { Ministro da Cultura e } \\
\text { Coordenação Científica }\end{array}$ \\
\hline $\begin{array}{c}\text { IX Governo Constitucional } \\
(1983-1985)\end{array}$ & $\begin{array}{l}\text { António Antero } \\
\text { Coimbra Martins }\end{array}$ & Ministério da Cultura & Ministro da Cultura \\
\hline $\begin{array}{c}\text { X Governo Constitucional } \\
(1985-1987)\end{array}$ & João de Deus Pinheiro & $\begin{array}{c}\text { Ministério da Educação } \\
\text { e Cultura }\end{array}$ & $\begin{array}{c}\text { Ministro da Educação } \\
\text { e Cultura }\end{array}$ \\
\hline $\begin{array}{c}\text { XI Governo Constitucional } \\
(1987-1991)\end{array}$ & Aníbal Cavaco Silva & $\begin{array}{c}\text { Presidência do Conselho } \\
\text { de Ministros }\end{array}$ & Primeiro-Ministro \\
\hline $\begin{array}{c}\text { XII Governo Constitucional } \\
(1991-1995)\end{array}$ & Aníbal Cavaco Silva & $\begin{array}{c}\text { Presidência do Conselho } \\
\text { de Ministros }\end{array}$ & Primeiro-Ministro \\
\hline $\begin{array}{c}\text { XIII Governo Constitucional } \\
(1995-1999)\end{array}$ & $\begin{array}{l}\text { Manuel Maria } \\
\text { Ferreira Carrilho }\end{array}$ & Ministério da Cultura & Ministro da Cultura \\
\hline \multirow{3}{*}{$\begin{array}{l}\text { XIV Governo Constitucional } \\
(1999-2002)\end{array}$} & $\begin{array}{l}\text { Manuel Maria Ferreira } \\
\text { Carrilho (1999-2000) }\end{array}$ & Ministério da Cultura & Ministro da Cultura \\
\hline & $\begin{array}{l}\text { José Estêvão Cangarato } \\
\text { Sasportes (2000-2001) }\end{array}$ & Ministério da Cultura & Ministro da Cultura \\
\hline & $\begin{array}{l}\text { Augusto Ernesto Santos } \\
\text { Silva (2001-2002) }\end{array}$ & Ministério da Cultura & Ministro da Cultura \\
\hline $\begin{array}{c}\text { XV Governo Constitucional } \\
(2002-2004)\end{array}$ & $\begin{array}{l}\text { Pedro Manuel } \\
\text { da Cruz Roseta }\end{array}$ & Ministério da Cultura & Ministro da Cultura \\
\hline $\begin{array}{l}\text { XVI Governo Constitucional } \\
(2004-2005)\end{array}$ & $\begin{array}{l}\text { Maria João Espírito } \\
\text { Santo Bustorff Silva }\end{array}$ & Ministério da Cultura & Ministra da Cultura \\
\hline \multirow{2}{*}{$\begin{array}{l}\text { XVII Governo Constitucional } \\
(2005-2009)\end{array}$} & $\begin{array}{c}\text { Maria Isabel da Silva Pires } \\
\text { de Lima (2005-2008) }\end{array}$ & Ministério da Cultura & Ministra da Cultura \\
\hline & $\begin{array}{l}\text { José António de Melo Pinto } \\
\text { Ribeiro (2008-2009) }\end{array}$ & Ministério da Cultura & Ministro da Cultura \\
\hline $\begin{array}{l}\text { XVIII Governo Constitucional } \\
(2009-2011)\end{array}$ & $\begin{array}{l}\text { Maria Gabriela da Silveira } \\
\text { Ferreira Canavilhas }\end{array}$ & Ministérios da Cultura & Ministra da Cultura \\
\hline
\end{tabular}

*Para o período entre 1976 e 2010 veja-se Guimarãis, Ayala, Machado e António (2011). 


\section{Anexo II}

\section{Quadro 2 - Secretários e Subsecretários de Estado da Cultura (1976-2011)*}

\begin{tabular}{|c|c|c|c|}
\hline Governo & Titular & Órgão & Cargo \\
\hline I Governo Constitucional (1976-78) & David Jesus Mourão-Ferreira & Secretaria de Estado da Cultura & Secretário de Estado da Cultura \\
\hline II Governo Constitucional (1978) & António Reis & Secretaria de Estado da Cultura & Secretário de Estado da Cultura \\
\hline III Governo Constitucional (1978) & $\begin{array}{c}\text { Maria Teresa Dória Monteiro } \\
\text { Santa Clara Gomes }\end{array}$ & $\begin{array}{c}\text { Secretaria de } \\
\text { Estado da Cultura }\end{array}$ & $\begin{array}{c}\text { Secretário de } \\
\text { Estado da Cultura }\end{array}$ \\
\hline $\begin{array}{c}\text { IV Governo Constitucional } \\
(1978-1979)\end{array}$ & David Jesus Mourão-Ferreira & Secretaria de Estado da Cultura & $\begin{array}{c}\text { Secretário de } \\
\text { Estado da Cultura }\end{array}$ \\
\hline $\begin{array}{c}\text { V Governo Constitucional } \\
(1979-1980) \\
\end{array}$ & Hélder Macedo & $\begin{array}{c}\text { Secretaria de } \\
\text { Estado da Cultura }\end{array}$ & $\begin{array}{c}\text { Secretário de } \\
\text { Estado da Cultura }\end{array}$ \\
\hline $\begin{array}{c}\text { VI Governo Constitucional } \\
(1980-1981) \\
\end{array}$ & Vasco Pulido Valente & $\begin{array}{c}\text { Secretaria de } \\
\text { Estado da Cultura }\end{array}$ & $\begin{array}{c}\text { Secretário de } \\
\text { Estado da Cultura }\end{array}$ \\
\hline $\begin{array}{c}\text { VII Governo Constitucional } \\
\text { (1981) }\end{array}$ & $\begin{array}{c}\text { António Manuel de } \\
\text { Assunção Braz Teixeira } \\
\end{array}$ & $\begin{array}{c}\text { Secretaria de } \\
\text { Estado da Cultura }\end{array}$ & $\begin{array}{c}\text { Secretário de } \\
\text { Estado da Cultura }\end{array}$ \\
\hline $\begin{array}{c}\text { VIII Governo Constitucional } \\
(1981-1983)\end{array}$ & $\begin{array}{l}\text { António José Tomás } \\
\text { Gomes de Pinho }\end{array}$ & $\begin{array}{c}\text { Secretaria de } \\
\text { Estado da Cultura }\end{array}$ & $\begin{array}{c}\text { Secretário de } \\
\text { Estado da Cultura }\end{array}$ \\
\hline $\begin{array}{c}\text { IX Governo Constitucional } \\
(1983-1985)\end{array}$ & --- & --- & --- \\
\hline $\begin{array}{c}\text { X Governo Constitucional } \\
(1985-1987)\end{array}$ & $\begin{array}{c}\text { Maria Teresa Pinto } \\
\text { Basto Gouveia }\end{array}$ & $\begin{array}{c}\text { Secretaria de } \\
\text { Estado da Cultura }\end{array}$ & $\begin{array}{c}\text { Secretária de } \\
\text { Estado da Cultura }\end{array}$ \\
\hline \multirow{3}{*}{$\begin{array}{l}\text { XI Governo Constitucional } \\
(1987-1991)\end{array}$} & $\begin{array}{c}\text { Maria Teresa Pinto Basto } \\
\text { Gouveia (1987-1990) }\end{array}$ & $\begin{array}{c}\text { Secretaria de E } \\
\text { stado da Cultura }\end{array}$ & $\begin{array}{c}\text { Secretário de } \\
\text { Estado da Cultura }\end{array}$ \\
\hline & $\begin{array}{c}\text { Pedro Santana Lopes } \\
(1990-1991)\end{array}$ & $\begin{array}{c}\text { Secretaria de } \\
\text { Estado da Cultura }\end{array}$ & $\begin{array}{c}\text { Secretário de } \\
\text { Estado da Cultura }\end{array}$ \\
\hline & $\begin{array}{l}\text { Maria Natália Brito da Silva } \\
\text { Correia Guedes (1990-1991) }\end{array}$ & $\begin{array}{c}\text { Secretaria de } \\
\text { Estado da Cultura }\end{array}$ & $\begin{array}{l}\text { Subsecretária de } \\
\text { Estado da Cultura }\end{array}$ \\
\hline \multirow{4}{*}{$\begin{array}{c}\text { XII Governo Constitucional } \\
(1991-1995)\end{array}$} & $\begin{array}{c}\text { Pedro Santana Lopes } \\
(1991-1994)\end{array}$ & $\begin{array}{c}\text { Secretaria de } \\
\text { Estado da Cultura }\end{array}$ & $\begin{array}{c}\text { Secretário de } \\
\text { Estado da Cultura }\end{array}$ \\
\hline & $\begin{array}{l}\text { Maria José Avillez Nogueira } \\
\text { Pinto (1991-1992) }\end{array}$ & $\begin{array}{c}\text { Secretaria de } \\
\text { Estado da Cultura }\end{array}$ & $\begin{array}{l}\text { Subsecretária Adjunta do } \\
\text { Secretário de Estado da Cultura }\end{array}$ \\
\hline & $\begin{array}{c}\text { António Costa de } \\
\text { Albuquerque de Sousa Lara } \\
\text { (1991-1992) }\end{array}$ & $\begin{array}{c}\text { Secretaria de } \\
\text { Estado da Cultura }\end{array}$ & $\begin{array}{l}\text { Subsecretário de } \\
\text { Estado da Cultura }\end{array}$ \\
\hline & $\begin{array}{c}\text { Manuel Barata Frexes } \\
(1992-1995)\end{array}$ & $\begin{array}{c}\text { Secretaria de } \\
\text { Estado da Cultura }\end{array}$ & $\begin{array}{l}\text { Subsecretário de } \\
\text { Estado da Cultura }\end{array}$ \\
\hline \multirow[b]{2}{*}{$\begin{array}{c}\text { XIII Governo Constitucional } \\
(1995-1999)\end{array}$} & Rui Vieira Nery (1995-1997) & Secretaria de Estado da Cultura & Secretário de Estado da Cultura \\
\hline & $\begin{array}{c}\begin{array}{c}\text { Catarina Marques de Almeida } \\
\text { Vaz Pinto (1997-1999) }\end{array} \\
\end{array}$ & $\begin{array}{c}\text { Secretaria de } \\
\text { Estado da Cultura }\end{array}$ & $\begin{array}{c}\text { Secretário de } \\
\text { Estado da Cultura }\end{array}$ \\
\hline \multirow{3}{*}{$\begin{array}{l}\text { XIV Governo Constitucional } \\
(1999-2002)\end{array}$} & $\begin{array}{c}\text { Catarina Marques de Almeida } \\
\text { Vaz Pinto (1999-2000) }\end{array}$ & $\begin{array}{c}\text { Secretaria de } \\
\text { Estado da Cultura }\end{array}$ & $\begin{array}{c}\text { Secretário de } \\
\text { Estado da Cultura }\end{array}$ \\
\hline & $\begin{array}{c}\text { João Alexandre do Nascimen- } \\
\text { to Batista (2000-2001) }\end{array}$ & $\begin{array}{c}\text { Secretaria de } \\
\text { Estado da Cultura }\end{array}$ & $\begin{array}{c}\text { Secretário de } \\
\text { Estado da Cultura }\end{array}$ \\
\hline & $\begin{array}{l}\text { José Manuel Conde Rodri- } \\
\text { gues (2001-2002) }\end{array}$ & $\begin{array}{c}\text { Secretaria de } \\
\text { Estado da Cultura }\end{array}$ & $\begin{array}{c}\text { Secretário de } \\
\text { Estado da Cultura }\end{array}$ \\
\hline $\begin{array}{c}\text { XV Governo Constitucional } \\
(2002-2004)\end{array}$ & José Manuel Amaral Lopes & Ministério da Cultura & $\begin{array}{l}\text { Secretário de Estado Adjunto } \\
\text { do Ministro da Cultura }\end{array}$ \\
\hline \multirow{2}{*}{$\begin{array}{l}\text { XVI Governo Constitucional } \\
(2004-2005)\end{array}$} & José Manuel Amaral Lopes & Ministério da Cultura & $\begin{array}{l}\text { Secretário de Estado } \\
\text { dos Bens Culturais }\end{array}$ \\
\hline & Teresa Caeiro & Ministério da Cultura & $\begin{array}{c}\text { Secretária de Estado } \\
\text { das Artes e Espetáculos }\end{array}$ \\
\hline \multirow{2}{*}{$\begin{array}{c}\text { XVII Governo Constitucional } \\
(2005-2009)\end{array}$} & $\begin{array}{c}\text { Mário Vieira de Carvalho } \\
(2005-2008) \\
\end{array}$ & Ministério da Cultura & $\begin{array}{c}\text { Secretário de } \\
\text { Estado da Cultura }\end{array}$ \\
\hline & $\begin{array}{l}\text { Maria Paula Fernandes } \\
\text { dos Santos (2008-2009) }\end{array}$ & Ministério da Cultura & $\begin{array}{c}\text { Secretária de } \\
\text { Estado da Cultura }\end{array}$ \\
\hline $\begin{array}{c}\text { XVIII Governo Constitucional } \\
(2009-2011) \\
\end{array}$ & $\begin{array}{l}\text { Elísio Costa Santos } \\
\text { Sumavielle }\end{array}$ & Ministério da Cultura & $\begin{array}{c}\text { Secretário de } \\
\text { Estado da Cultura }\end{array}$ \\
\hline
\end{tabular}

*Para o período entre 1976 e 2010 veja-se Guimarãis, Ayala, Machado e António (2011). 


\section{Referências bibliográficas}

ADORNO, Theodor W. 2003. Sobre a indústria da cultura. Coimbra: Angelus Novus Editora.

ALMEIDA, Pedro Tavares de \& PINTO, António Costa. 2009. "Portugal: the primacy of 'independents"'. In: DOWDING, Keith \& DUMONT, Patrick (eds.). The selection of ministers in Europe: hiring and firing. London: Routledge.

\& BERMEO, Nancy. 2006. Quem governa a Europa do Sul? O recrutamento ministerial, 1850-2000. Lisboa: Instituto de Ciências Sociais.

BARRETO, António. 2011. “Os livros com assinatura e quem está no governo". Jornal Público, 4 de setembro, p. 8-11.

BESSA, António Marques. 1993. Quem governa? Uma análise histórico-política do tema da elite. Lisboa: Instituto Superior de Ciências Sociais e Políticas.

BOTTOMORE, Thomas Burton. 1964. Elites and society. London: C. A. Watts \& Co. Ltd.

COTTA, Maurizio. 2008 Democracia, partidos e elites políticas. Lisboa: Livros Horizonte.

DEBORD, Guy. 2010. La société du spectacle. Paris: Editions Gallimard.

DIJAN, Jean-Michel. 2005. Politique culturelle: la fin d'un mythe. Paris: Editions Gallimard.

DOWDING, Keith \& DUMONT, Patrick (eds.). 2009. The selection of ministers in Europe: hiring and firing. London: Routledge.

GARCÊS, Ana Paula 2009. "Profissionalismo político e representação". In: CABRAL, Manuel V.; LOBO, Marina C. \& FEIJÓ, Rui G. (org.). Portugal uma democracia consolidada: ensaios de homenagem a David B. Goldey. Lisboa: Instituto de Ciências Sociais.

GUEDES, Nuno. 2009. "Quem lidera os governos europeus? A carreira dos primeiros-ministros (1946-2006)”. Análise Social, v. XLIV, n. 191, p.265-288. GUIMARÃIS, Alberto L.; AYALA, Bernardo D.; MACHADO, Manuel P. \& ANTÓNIO, Miguel F. 2011. Os governos da república (1910-2010). Lisboa: Edição de Autor.

HUNTINGTON, Samuel P. 1999. The third wave: democratization in the late twentieth century. London: University of Oklahoma Press.

INGLEHART, Ronald. 1990. Culture shift in advanced industrial society. Princeton/ New Jersey: Princeton University Press. 
MAGONE, J. M. 2003 "Portugal: the patrimonial heritage and the emergence of a democratic political class". In: BORCHERT, Jens \& ZEISS, Jürgen (eds.). The political class in advanced democracies. Oxford: Oxford University Press.

NORRIS, Pippa (ed.). 1999. Critical citizens: global support for democratic governance. New York: Oxford University Press.

PARETO, Vilfredo. 1975. Faits et théories. Genève: Librairie Droz.

PRATT, Andy C. 2007 "O estado da economia cultural: o crescimento da economia e os desafios da definição de uma política cultural”. In: AAVV (eds.). A urgência da teoria: o estado do mundo. Lisboa: Edições tinta da China.

SARMENTO, Cristina Montalvão. 2008. Guardiões dos sonhos: teorias e práticas políticas dos anos 60. Lisboa: Colibri.

. 2009. "As 'vantagens' atuais da cultura". In: GODINHO, Paula; BASTOS, Susana P. \& FONSECA, Ines (orgs.). Jorge Crespo: estudos de homenagem. Lisboa: 100LUZ.

SEABRA, Augusto M. 2011a. "O imbróglio dos museus nacionais". Jornal Público, caderno Y, 15 de abril, p.46.

. 2011b. "O nó da Cultura". Jornal Público, caderno Y, 3 de junho, p. 46.

WEBER, Max. 1979. O político e o cientista. $3^{\text {a }}$ ed. Lisboa: Presença.

\section{Resumo}

Com base numa análise prosopográfica, este artigo incide sobre os padrões de recrutamento da elite governante da cultura. $O$ universo em análise compreende os membros da elite governante da cultura em Portugal, desde o I ao XVIII Governos Constitucionais, no período entre 1976 e 2011. Esta análise tem em consideração as características demográficas (idade e género), as credenciais académicas, as carreiras profissionais e políticas, bem como eventuais competências no setor da cultura dos Ministros e Secretários de Estado da Cultura. Este artigo propõe igualmente, uma análise comparativa dos perfis desta elite governante, em Portugal.

Palavras-chave: cultura; elite; governo; método prosopográfico; política; Portugal.

\section{Abstract}

Based on a prosopographical analysis, this paper focuses on recruitment patterns of the ruling elite within culture. The universe examined comprises members of the ruling elite in Portugal's culture, from the $1^{\text {st }}$ to the $18^{\text {th }}$ Constitutional Governments, spanning 
the 1976-2011 period. This analysis takes into account demographic characteristics (age and gender); academic credentials; professional and political careers; as well as eventual cultural skills of Culture Ministers and State Secretaries. This paper also proposes a comparative analysis of profiles of the ruling elite in Portugal's culture.

Key words: culture; elite; government; prosopographical method; politics; Portugal.

Recebido em 31 de janeiro de 2012.

Aprovado em 14 de maio de 2012. 